\title{
The association between diurnal temperature range and childhood hand, foot, and mouth disease: a distributed lag non-linear analysis
}

\author{
FEI YIN ${ }^{1}$, YUE MA ${ }^{1}$, XING ZHAO ${ }^{1}$, QIANG LV ${ }^{2}$, YAQIONG LIU ${ }^{2}$, \\ TAO ZHANG ${ }^{1 *}$ AND XIAOSONG LI ${ }^{1}$ \\ ${ }^{1}$ West China School of Public Health, Sichuan University, Chengdu, Sichuan, People's Republic of China \\ ${ }^{2}$ Sichuan Center for Disease Control and Prevention, Chengdu, Sichuan, People's Republic of China
}

Received 7 July 2017; Final revision 28 August 2017; Accepted 12 September 2017;

first published online 17 October 2017

\section{SUMMARY}

In recent years, hand, foot, and mouth disease (HFMD) has been increasingly recognized as a critical challenge to disease control and prevention in China. Previous studies have found that meteorological factors such as mean temperature and relative humidity were associated with HFMD. However, little is known about whether the diurnal temperature range (DTR) has any impact on HFMD. This study aimed to quantify the impact of DTR on childhood HFMD in 18 cities in Sichuan Province. A distributed lag non-linear model was adopted to explore the temporal lagged association of daily temperature with age-, gender- and pathogen-specific HFMD. A total of 290123 HFMD cases aged 0-14 years were reported in the 18 cities in Sichuan Province. The DTR-HFMD relationships were non-linear in all subgroups. Children aged 6-14 years and male children were more vulnerable to the temperature changes. Large DTR had the higher risk estimates of HFMD incidence in cases of EV71 infection, while small DTR had the higher risk estimates of HFMD incidence in cases of CV-A16 infection. Our study suggested that DTR played an important role in the transmission of HFMD with non-linear and delayed effects.

Key words: Foot and mouth disease, hand.

\section{INTRODUCTION}

Hand, foot, and mouth disease (HFMD) is a worldwide childhood infectious disease mainly caused by coxsackie virusA16 (CV-A16) and enterovirus 71 (EV71) [1, 2]. The main clinical symptoms of HFMD include mouth ulcers, fever, and vesicles on the hands, feet, and mouth [3]. In most cases, the disease is mild and self-limiting. But some patients may develop serious cardiopulmonary and neurological

\footnotetext{
* Author for correspondence: T. Zhang, West China School of Public Health, Sichuan University, No.16 Section 3, Renminnan Road, Chengdu, Sichuan 610041, People's Republic of China. (Email: theoresver@163.com)
}

complications, and such cases are mainly caused by EV71 [4].

In recent decades, Asia-Pacific countries have experienced an increasing trend of HFMD outbreaks [5-8]. In particular, the epidemic situation of HFMD in China is quite serious. In 2014, for example, over 2.7 million HFMD cases were reported to the China Center for Disease Control and Prevention, including 501 fatal cases. The public health threat caused by HFMD pushes the need to identify environmental predictors, which have significant impacts on HFMD.

It is well accepted that meteorological factors play important roles in the transmission of many communicable diseases [9-13]. Epidemiologists have 
conducted a large amount of researchers to quantify the associations between meteorological variables and HFMD. Meteorological factors such as mean temperature and relative humidity are the most commonly reported environmental agents. However, to date, the effect of temperature variation on childhood HFMD has received limited attention. The temperature variation within one calendar day, i.e., diurnal temperature range (DTR), is an important indicator for climate change. Previous studies have reported that DTR is associated with many infectious diseases (e.g. diarrhoea, pneumonia and respiratory syncytial virus) [14-16]. But few studies have examined the impact of DTR on children's health, and little is known about the relationship between DTR and childhood HFMD. To the best of our knowledge, there are only three published papers focusing on the relationship between DTR and HFMD [15, 17, 18]. But these findings are inconsistent, and the nature and extent of the relationship remain highly controversial. In addition, no studies have assessed the age-, gender- and pathogen-specific effects of DTR on childhood HFMD. The current study was designed to help address this research gap.

This study aimed to quantify the lag association between DTR and HFMD. Specifically, a multilevel distributed lag non-linear model (DLNM) was adopted to explore the temporal lagged relationship between daily HFMD cases and daily DTR using the data in 18 cities in Sichuan Province, China. Using the more sophisticated model, a better understanding might be achieved for the relationship between DTR and HFMD.

\section{MATERIALS AND METHODS}

\section{Study area}

Sichuan Province is located in Southwest China between longitude $98 \cdot 31 \mathrm{E}$ to $107 \cdot 99 \mathrm{E}$ and latitude $26 \cdot 40 \mathrm{~N}$ to $33 \cdot 68 \mathrm{~N}$. It has a population of approximately 80 million people and encompasses $485000 \mathrm{~km}^{2}$. There are 18 prefectural-level cities in Sichuan Province.

\section{Data sources}

In China, a web-based infectious disease monitor information system (the China Information System for Disease Control and Prevention, CISDCP) has been established in 2004. HFMD was classified as a class "C" notifiable disease by the Ministry of Health of China. Therefore, all HFMD cases should be reported to CISDCP within $24 \mathrm{~h}$ after diagnosis using a unified format [19]. The diagnosis of HFMD was made according to the clinical criteria issued by the Ministry of Health of China [19]. The city-specific daily data of reported HFMD cases in 18 prefecturallevel cities in Sichuan Province from 2011 to 2015 were obtained from CISDCP. As $99 \%$ of cases occurred among children under the age of 15 years according to the preliminary analysis, we focused on the HFMD cases aged 0-14 years in this study.

Daily meteorological data, including maximum temperature, mean temperature, minimum temperature, relative humidity and rainfall of 18 cities in Sichuan Province were obtained from China Meteorological Data Sharing Service System. DTR was calculated as daily maximum temperature minus daily minimum temperature. The city-specific socioeconomic data from 2011 to 2015 were collected from the China city statistical year book.

\section{Distributed lag non-linear models}

DLNM represent a flexible modelling framework that can flexibly describe a non-linear exposure-response relationship and delayed effects in time series data [20]. In this study, a Poisson generalized linear regression combined with DLNM was applied to explore the effect of DTR on HFMD incidence. The model was specified as:

$$
\begin{aligned}
\log \left[E\left(Y_{t}\right)\right]= & \alpha+c b(\text { temp })+n s(\text { humid })+\beta_{1} \text { GDP } \\
& +\beta_{2} \text { Density }+\beta_{3} \text { Trend }+\beta_{4} \text { Dow } \\
& +\beta_{5} \text { Holiday }+\log (\text { pop })
\end{aligned}
$$

where $Y_{t}$ is the reported daily HFMD case counts on day $t ; \alpha$ is the intercept; Pop is the population. cb (temp) indicates the 'cross-basis' function, which is obtained by DLNM to model non-linear and distributed lag effects of temperature. ns means a smooth function based on the natural cubic spline. A natural cubic spline DLNM was used to model the nonlinear association between DTR and HFMD. Akaike Information Criterion (AIC) was adopted to choose the degrees of freedom (df) for DTR and lag [20]. The final composition of the function was a natural cubic spline of DTR with three df and a natural cubic spline with three df for lag days. Based on previous studies [12, 13], a maximum lag of 14 days was used to explore the potential lag associations. 
Three df was used to smooth humidity (humid) and rainfall (rain) [12, 13]. GDP (GDP per person) and Density (population density) are socio-economic variables. Trend is a variable of the year and calendar month used to control for seasonality and long-term trend. Dow is a day of the week on day $t$. Holiday is a binary variable which is ' 1 ' if day $t$ was a public holiday. $\beta_{1}, \beta_{2}, \beta_{3}, \beta_{4}$ and $\beta_{5}$ are the regression coefficients. Rainfall was insignificantly associated with HFMD, so the variable was removed from the final model.

The 18 cities were divided into two groups: group B (Panzhihua city) and group A (the other 17 cities), since small differences in weather conditions (Table 1) were detected within cities except for Panzhihua city. For group A, stratified analyses were performed by gender group (male and female), age group (0-5 and 6-14 years) and pathogen group (EV71 and CV-A16). For group B, stratified analyses were performed by gender group and age group. We did not perform pathogen-specific analysis for group B because there were only 521 laboratory-confirmed cases in Panzhihua city (206 cases were associated with EV71 and 155 cases were associated with CVA16).

Sensitive analyses were performed to test the robustness of our results: varying the $\mathrm{df}(4-7)$ for meteorological variables. The 'dlnm' and 'Ime4' packages in the $\mathrm{R}$ software (version $3 \cdot 3 \cdot 3$ ) were used to create the multilevel DLNM model.

\section{RESULTS}

A total of 290123 HFMD cases aged 0-14 years were reported in the 18 cities in Sichuan Province during 1 January 2011 and 31 December 2015, of which 19632 $(6 \cdot 77 \%)$ were laboratory confirmed. On average, there were 8.83 cases of daily HFMD. Children aged $0-5$ years were the majority of the victims, which accounted for $97 \cdot 25 \%$ (282 149 cases) of all reported cases over the study period. Of 290123 HFMD cases, 174026 were males and 116097 were females, with a male-to-female sex ratio 1.50. Among the laboratory confirmed cases, $6166(31.41 \%)$ were associated with EV71 and 4639 (23.63\%) were associated with CV-A16. Table 1 presented the descriptive analysis for the 18 cities.

\section{Results of group A}

The three-dimensional plot demonstrated the relationship between daily DTR and HFMD cases along 14 lag days (Fig. 1). Overall, the estimated effects of DTR on HFMD incidence were non-linear, with higher relative risk (RR) at large DTR.

Figure 2 showed the overall effect of temperature, summing up the contributions for the 14 days of lag. It suggested that DTR was significantly associated with childhood HFMD. The RR increased with the increment of DTR and it reached the small peak at $5 \cdot 2{ }^{\circ} \mathrm{C}$ and then the curve became relatively flat, again the RR increased rapidly when DTR was above $8.7^{\circ} \mathrm{C}$.

Figure 3 presented the RR of cumulative exposure to DTR over 14 days for age-, gender- and pathogenspecific HFMD cases. For males and females, the RR followed the similar trends as the total RR, with the first small peak at $5.2{ }^{\circ} \mathrm{C}$ for males and $5.0{ }^{\circ} \mathrm{C}$ for females. For these two groups, the RR began to increase rapidly when DTR was above $8.7^{\circ} \mathrm{C}$. But For males, the RR increased more rapidly than that of females.

For children aged $0-5$ years and $6-14$ years, the RR also followed the similar trends as the total RR. For children aged $0-5$ years, the $\mathrm{RR}$ reached the small peak at $5 \cdot 1{ }^{\circ} \mathrm{C}$ and began to increase rapidly when DTR was above $8.7{ }^{\circ} \mathrm{C}$. For children aged $6-14$ years, the curve became relatively flat when DTR was above $5.5^{\circ} \mathrm{C}$. Again the RR increased rapidly when DTR was above $8.7^{\circ} \mathrm{C}$.

Figure 3 also illustrated the cumulative effects of DTR on pathogen-specific HFMD cases. The exposure-response curve of DTR on EV71 was quite different from that of CV-A16. For cases of EV71 infection, the $\mathrm{RR}$ reached the small peak at $6.5^{\circ} \mathrm{C}$ and then the curve became relatively flat. Again the RR increased very rapidly when DTR was above $8.7^{\circ} \mathrm{C}$. For cases of CV-A16 infection, the RR reached the peak at $6 \cdot 6^{\circ} \mathrm{C}$ and then the curve began to decrease.

The risks of different DTRs for total, gender-, ageand pathogen-specific HFMD cases along the lags were summarized in Table 2. The effects of DTR on childhood HFMD differed between males and females. We found that DTR had the higher risk estimates of HFMD incidence in males than in females. For females, the RR value was 1.57 (95\% CI 1.50 1.63 ) at lag0-14 when DTR was $12 \cdot 3{ }^{\circ} \mathrm{C}$. While for males, the RR value was 1.60 (95\% CI 1.54-1.65) at lag0-14. For age-specific RRs, DTR had the higher risk estimates of HFMD incidence in children aged 6-14 years. For children aged $0-5$ years, the RR value was $1.57(95 \%$ CI $1.53-1 \cdot 61)$ at lag0-14 when DTR was $12 \cdot 3{ }^{\circ} \mathrm{C}$. For children aged $6-14$ years, the RR value was 1.66 (95\% CI 1.48-1.85) at lag0-14. 
Table 1. Characteristics of the 18 cities in Sichuan Province

\begin{tabular}{lllllll}
\hline \hline City & Cases & DTR $\left({ }^{\circ} \mathrm{C}\right)$ & $\begin{array}{l}\text { Mean } \\
\text { temperature }\left({ }^{\circ} \mathrm{C}\right)\end{array}$ & $\begin{array}{l}\text { Relative } \\
\text { humidity }(\%)\end{array}$ & $\begin{array}{l}\text { GDP per } \\
\text { capita }(\mathrm{RMB})\end{array}$ & $\begin{array}{l}\text { Population density } \\
\left(\text { people per km }{ }^{2}\right)\end{array}$ \\
\hline Chengdu & 122564 & $7 \cdot 91$ & $16 \cdot 33$ & $78 \cdot 47$ & $65464 \cdot 70$ & $983 \cdot 76$ \\
Zigong & 5312 & $6 \cdot 75$ & $18 \cdot 12$ & $78 \cdot 86$ & $34565 \cdot 43$ & $750 \cdot 05$ \\
Panzhihua & 5443 & $12 \cdot 18$ & $21 \cdot 37$ & $52 \cdot 59$ & $66127 \cdot 66$ & $150 \cdot 76$ \\
Luzhou & 4977 & $6 \cdot 56$ & $18 \cdot 01$ & $82 \cdot 78$ & $25894 \cdot 14$ & $413 \cdot 84$ \\
Deyang & 14632 & $7 \cdot 35$ & $17 \cdot 03$ & $74 \cdot 83$ & $38380 \cdot 67$ & $662 \cdot 06$ \\
Mianyang & 16687 & $7 \cdot 02$ & $17 \cdot 26$ & $70 \cdot 47$ & $29743 \cdot 53$ & $269 \cdot 55$ \\
Guangyuan & 7068 & $8 \cdot 16$ & $16 \cdot 68$ & $67 \cdot 57$ & $19392 \cdot 78$ & $189 \cdot 83$ \\
Suining & 10842 & $7 \cdot 13$ & $17 \cdot 50$ & $75 \cdot 55$ & $22285 \cdot 45$ & $712 \cdot 83$ \\
Neijiang & 10199 & $7 \cdot 11$ & $17 \cdot 79$ & $80 \cdot 77$ & $27509 \cdot 36$ & $789 \cdot 38$ \\
Leshan & 11427 & $6 \cdot 71$ & $18 \cdot 05$ & $77 \cdot 90$ & $33538 \cdot 07$ & $278 \cdot 62$ \\
Nanchong & 12931 & $6 \cdot 64$ & $18 \cdot 26$ & $77 \cdot 59$ & $19832 \cdot 81$ & $605 \cdot 23$ \\
Meishan & 21107 & $7 \cdot 17$ & $17 \cdot 21$ & $78 \cdot 95$ & $27886 \cdot 46$ & $491 \cdot 08$ \\
Yibing & 5916 & $6 \cdot 61$ & $18 \cdot 62$ & $74 \cdot 01$ & $28616 \cdot 19$ & $413 \cdot 86$ \\
Guangan & 5819 & $7 \cdot 00$ & $17 \cdot 89$ & $75 \cdot 23$ & $24256 \cdot 74$ & $739 \cdot 90$ \\
Dazhou & 9124 & $7 \cdot 24$ & $17 \cdot 92$ & $72 \cdot 54$ & $21202 \cdot 52$ & $415 \cdot 44$ \\
Yaan & 7199 & $6 \cdot 94$ & $16 \cdot 68$ & $78 \cdot 66$ & $27699 \cdot 35$ & $103 \cdot 87$ \\
Bazhong & 9054 & $7 \cdot 86$ & $17 \cdot 18$ & $74 \cdot 20$ & $12350 \cdot 31$ & $314 \cdot 39$ \\
Ziyang & 9822 & $7 \cdot 38$ & $17 \cdot 21$ & $78 \cdot 27$ & $28210 \cdot 29$ & $635 \cdot 21$ \\
\hline
\end{tabular}

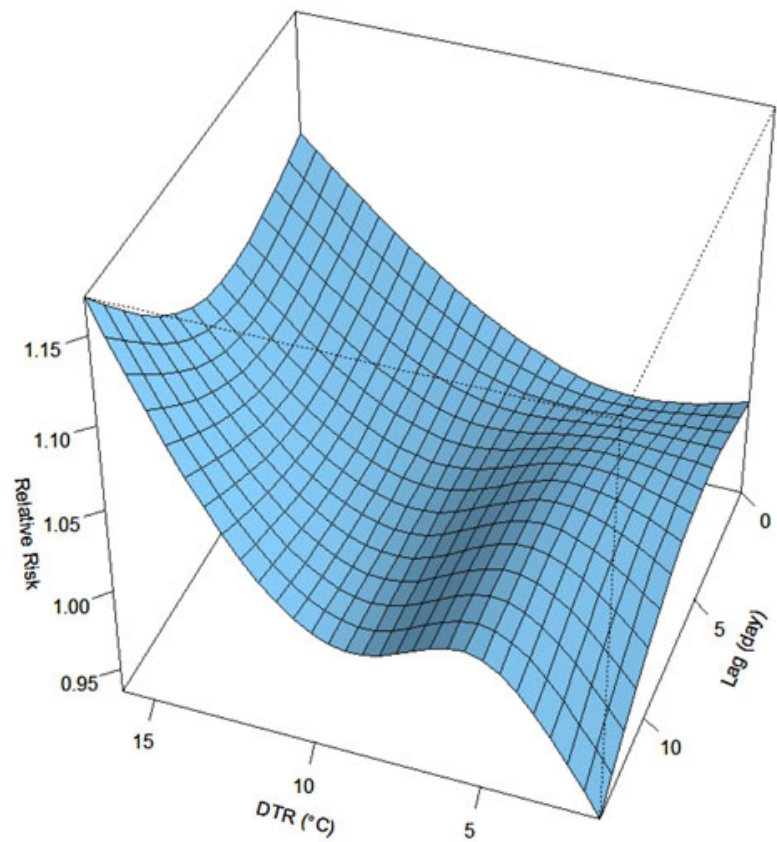

Fig. 1. Three-dimensional plot of the relationship between DTR and HFMD over 14 lag days (group A).

For pathogen-specific RRs, large DTR had the higher risk estimates of HFMD incidence in cases of EV71 infection, while small DTR had the higher risk estimates of HFMD incidence in cases of CV-A16 infection. For cases of EV71 infection, the RR value was $2.63(95 \%$ CI $2 \cdot 29-3.03)$ at lag0-14 when DTR was $12 \cdot 3{ }^{\circ} \mathrm{C}$. For cases of $\mathrm{CV}-\mathrm{A} 16$

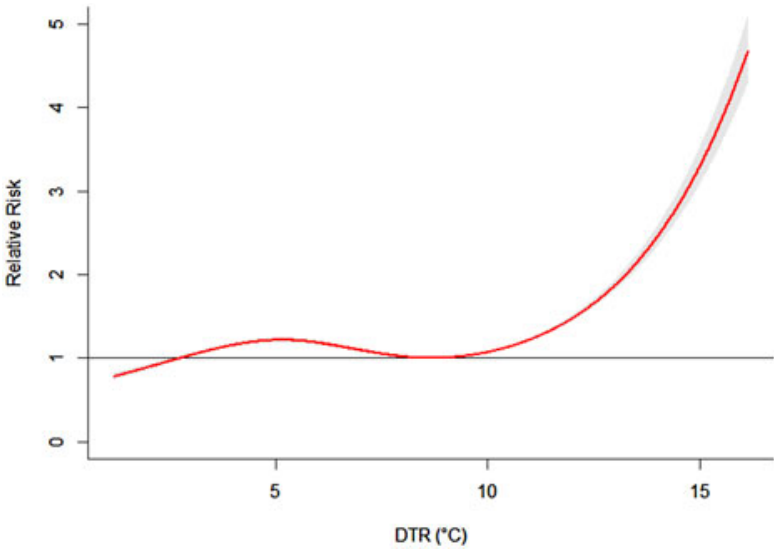

Fig. 2. The overall relative risks of DTR for total HFMD cases over 14 days (group A).

infection, the RR value was $0 \cdot 81(95 \%$ CI $0 \cdot 66-1 \cdot 00)$ at $\operatorname{lag} 0-14$.

In the sensitivity analyses, when the $\mathrm{df}$ for climate variables were varied between 4 and 7 , similar results were obtained.

\section{Results of group B}

The three-dimensional graph presented the relationship between daily DTR and HFMD cases along 14 lag days (Fig. 4). Overall, the estimated effects of DTR on HFMD incidence were non-linear, with higher RR at large DTR. 

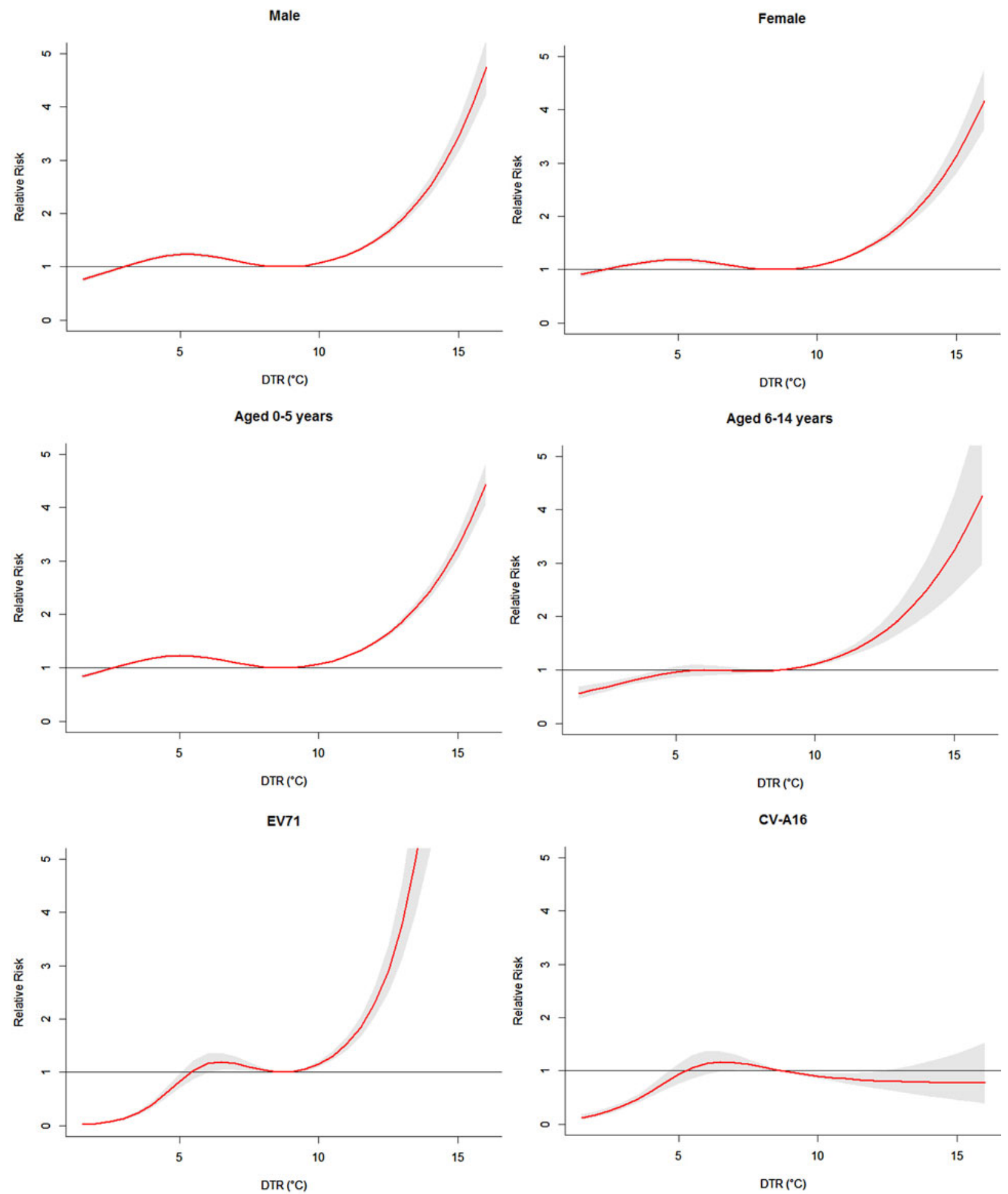

Fig. 3. The overall relative risks of DTR for age-, gender- and pathogen-specific HFMD cases over 14 days (group A).

Figure 5 showed the overall effect of temperature. It suggested that DTR was significantly associated with childhood HFMD. The exposure-response curve was an approximately inverted V-shape. The RR increased with the increment of DTR and it reached the peak at $13.7^{\circ} \mathrm{C}$ and then began to decrease.

Figure 6 demonstrated the RR of cumulative exposure to humidex over 14 days for age- and gender- 
Table 2. The relative risks of different diurnal temperature ranges for age-, gender- and pathogen-specific HFMD cases (group A)

\begin{tabular}{|c|c|c|c|c|}
\hline & \multirow[b]{2}{*}{$\operatorname{DTR}\left({ }^{\circ} \mathrm{C}\right)^{*}$} & \multicolumn{3}{|l|}{$\mathrm{RR}(95 \% \mathrm{CI})$} \\
\hline & & Lag0 & Lag7 & Lag0-14 (overall effect) \\
\hline \multirow[t]{3}{*}{ Total } & $5 \cdot 2$ & $0.98(0.98-0.99)$ & $1 \cdot 02(1 \cdot 02-1 \cdot 03)$ & $1 \cdot 22(1 \cdot 19-1 \cdot 25)$ \\
\hline & $9 \cdot 4$ & $1 \cdot 01(1 \cdot 01-1 \cdot 01)$ & $1.00(1.00-1 \cdot 00)$ & $1 \cdot 02(1 \cdot 02-1 \cdot 03)$ \\
\hline & $12 \cdot 3$ & $1 \cdot 04(1 \cdot 04-1 \cdot 05)$ & $1.02(1.02-1 \cdot 02)$ & $1.58(1.54-1.63)$ \\
\hline \multirow[t]{3}{*}{ Male } & $5 \cdot 2$ & $0.98(0.97-0.98)$ & $1.03(1.02-1.03)$ & $1 \cdot 24(1 \cdot 20-1 \cdot 28)$ \\
\hline & $9 \cdot 4$ & $1 \cdot 01(1 \cdot 01-1 \cdot 01)$ & $1 \cdot 00(1 \cdot 00-1 \cdot 00)$ & $1 \cdot 02(1 \cdot 01-1 \cdot 02)$ \\
\hline & $12 \cdot 3$ & $1 \cdot 05(1 \cdot 04-1 \cdot 05)$ & $1 \cdot 02(1 \cdot 02-1 \cdot 02)$ & $1.60(1.54-1.65)$ \\
\hline \multirow[t]{3}{*}{ Female } & $5 \cdot 2$ & $0.99(0 \cdot 98-1 \cdot 00)$ & $1 \cdot 01(1 \cdot 01-1 \cdot 02)$ & $1 \cdot 18(1 \cdot 14-1 \cdot 23)$ \\
\hline & $9 \cdot 4$ & $1 \cdot 01(1 \cdot 00-1 \cdot 01)$ & $1 \cdot 00(1 \cdot 00-1 \cdot 00)$ & $1 \cdot 03(1 \cdot 02-1 \cdot 03)$ \\
\hline & $12 \cdot 3$ & $1 \cdot 04(1 \cdot 03-1 \cdot 05)$ & $1 \cdot 02(1 \cdot 02-1 \cdot 03)$ & $1 \cdot 57(1 \cdot 50-1 \cdot 63)$ \\
\hline \multirow[t]{3}{*}{$0-5$ years } & $5 \cdot 2$ & $0.98(0.98-0.99)$ & $1 \cdot 02(1 \cdot 02-1 \cdot 03)$ & $1 \cdot 23(1 \cdot 20-1 \cdot 26)$ \\
\hline & $9 \cdot 4$ & $1 \cdot 01(1 \cdot 01-1 \cdot 01)$ & $1 \cdot 00(1 \cdot 00-1 \cdot 00)$ & $1 \cdot 02(1 \cdot 02-1 \cdot 03)$ \\
\hline & $12 \cdot 3$ & $1 \cdot 04(1 \cdot 04-1 \cdot 05)$ & $1 \cdot 02(1 \cdot 02-1 \cdot 02)$ & $1 \cdot 57(1.53-1 \cdot 61)$ \\
\hline \multirow[t]{3}{*}{$6-14$ years } & $5 \cdot 2$ & $0.97(0.94-0.99)$ & $1.00(0.99-1.02)$ & $0.98(0.88-1.09)$ \\
\hline & $9 \cdot 4$ & $1 \cdot 01(1 \cdot 00-1 \cdot 01)$ & $1 \cdot 00(1 \cdot 00-1 \cdot 00)$ & $1.05(1.03-1 \cdot 07)$ \\
\hline & $12 \cdot 3$ & $1 \cdot 03(1 \cdot 00-1 \cdot 05$ & $1.03(1.02-1 \cdot 04)$ & $1.66(1.48-1.85)$ \\
\hline \multirow[t]{3}{*}{ EV71 } & $5 \cdot 2$ & $0.99(0.96-1.03)$ & $1.00(0.98-1.02)$ & $0.92(0.78-1.09)$ \\
\hline & $9 \cdot 4$ & $1.00(1 \cdot 00) 1 \cdot 01$ & $1 \cdot 00(1 \cdot 00-1 \cdot 01)$ & $1.04(1.02-1.07)$ \\
\hline & $12 \cdot 3$ & $1 \cdot 08(1 \cdot 05-1 \cdot 11)$ & $1 \cdot 07(1 \cdot 05-1 \cdot 08)$ & $2 \cdot 63(2 \cdot 29-3 \cdot 03)$ \\
\hline \multirow[t]{3}{*}{ CV-A16 } & $5 \cdot 2$ & $0.98(0.93-1.02)$ & $1 \cdot 01(0.98-1 \cdot 03)$ & $0.99(0 \cdot 80-1 \cdot 21)$ \\
\hline & $9 \cdot 4$ & $1.00(0 \cdot 99-1 \cdot 01)$ & $1.00(0.99-1.00)$ & $0.94(0.91-0.97)$ \\
\hline & $12 \cdot 3$ & $0.98(0.94-1.03)$ & $0.98(0.96-1.00)$ & $0 \cdot 81(0 \cdot 66-1 \cdot 00)$ \\
\hline
\end{tabular}

$* 9 \cdot 4^{\circ} \mathrm{C}$ and $12 \cdot 3{ }^{\circ} \mathrm{C}$ represented the 75 th percentile and 95 th percentile of DTR, respectively; $5 \cdot 2{ }^{\circ} \mathrm{C}$ represented the first small peak value of DTR for total children.

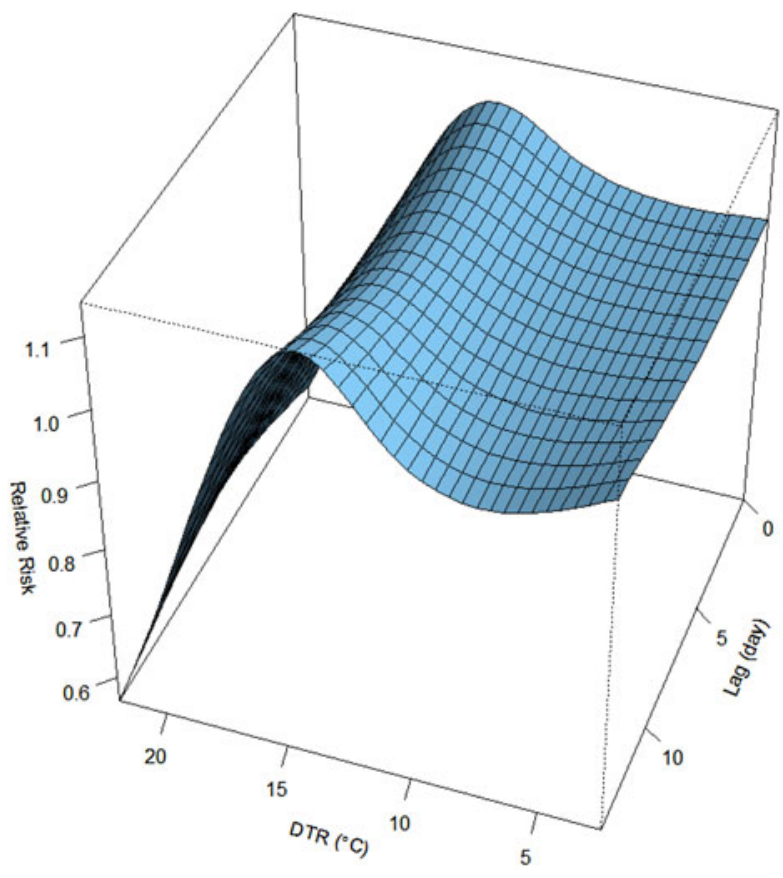

Fig. 4. Three-dimensional plot of the relationship between DTR and HFMD over 14 lag days (group B).

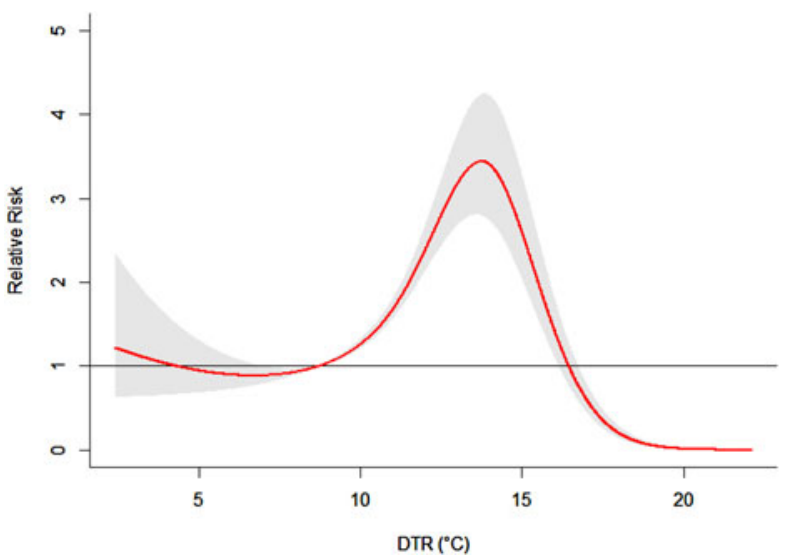

Fig. 5. The overall relative risks of DTR for total HFMD cases over 14 days (group B).

specific HFMD cases. For males and females, the RRs followed the similar trends as the total RR, with the peak at $13.6{ }^{\circ} \mathrm{C}$ for males and $13.8{ }^{\circ} \mathrm{C}$ for females. For children aged $0-5$ years and $6-14$ years, the exposure-response curves also followed the similar 

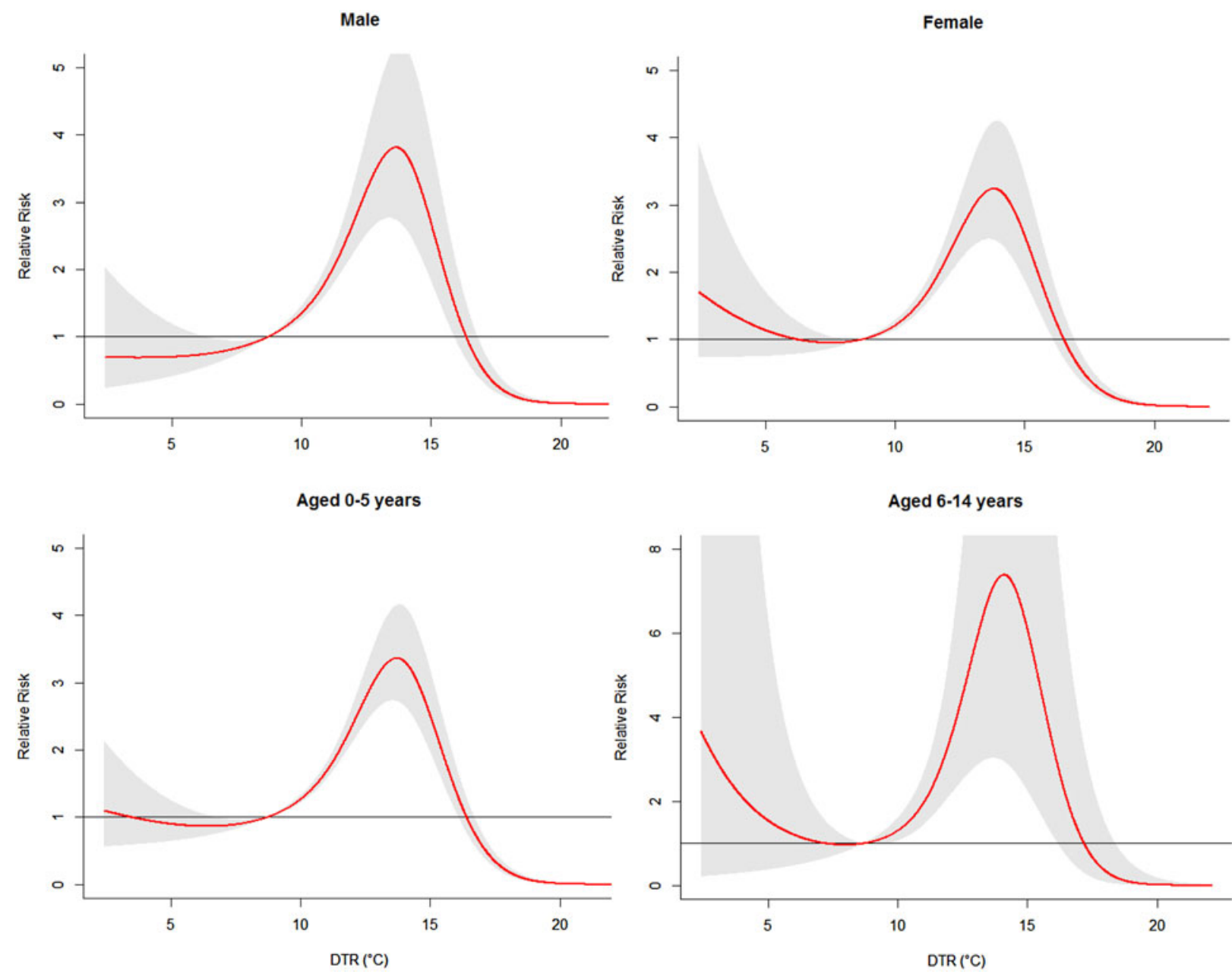

Fig. 6. The overall relative risks of DTR for age- and gender-specific HFMD cases over 14 days (group B).

trends as the total $\mathrm{RR}$, with the peak at $13.7^{\circ} \mathrm{C}$ for children aged $0-5$ years and $14 \cdot 1{ }^{\circ} \mathrm{C}$ for children aged $6-14$ years.

The risks of different DTR for total, gender- and age-specific HFMD cases along the lags were summarized in Table 3. The effects of DTR on childhood HFMD differed between males and females. We found that DTR had the higher risk estimates of HFMD incidence in males than in females. For males, the highest RR value was $3 \cdot 80$ (95\% CI $2 \cdot 70$ $5 \cdot 34)$ at lag0-14. While for females, the highest RR value was $3 \cdot 24(95 \%$ CI $2 \cdot 48-4 \cdot 24)$ at lag0-14. For age-specific RRs, DTR had the higher risk estimates of HFMD incidence in children aged 6-14 years. For children aged $0-5$ years, the highest $R R$ value was $3.37(95 \%$ CI $2 \cdot 73-4 \cdot 15)$ at lag0-14. While for children aged $6-14$ years, the highest RR value was $7 \cdot 24(95 \%$ CI $3 \cdot 02-17 \cdot 35)$ at $\operatorname{lag} 0-14$.
In the sensitivity analyses, when the df for climate variables were varied between 4 and 7 , similar results were obtained.

\section{DISCUSSION}

Our study investigated the association of DTR with age-, gender- and pathogen-specific HFMD among children. A DLNM was adopted to explore the temporal lagged association of daily DTR with HFMD. This is, to our knowledge, the first study to assess the pathogen-specific effects of DTR on HFMD.

In this study, DLNM was adopted to explore the non-linear and lagged relationship between DTR and HFMD. The results of this study indicated that there was a significant association between DTR and childhood HFMD. Although the exact mechanism remains largely unknown, it is possible that DTR 
Table 3. The relative risks of different diurnal temperature ranges for age- and gender-specific HFMD cases (group B)

\begin{tabular}{|c|c|c|c|c|}
\hline & \multirow[b]{2}{*}{$\operatorname{DTR}\left({ }^{\circ} \mathrm{C}\right)^{*}$} & \multicolumn{3}{|l|}{$\operatorname{RR}(95 \% \mathrm{CI})$} \\
\hline & & $\operatorname{Lag} 0$ & $\operatorname{Lag} 7$ & Lag0-14 (overall effect) \\
\hline \multirow[t]{3}{*}{ Total } & $13 \cdot 7^{\dagger}$ & $1 \cdot 08(1 \cdot 03-1 \cdot 03)$ & $1 \cdot 07(1 \cdot 04-1 \cdot 09)$ & $3 \cdot 44(2 \cdot 80-4 \cdot 23)$ \\
\hline & $14 \cdot 8$ & $1 \cdot 06(1 \cdot 01-1 \cdot 11)$ & $1.05(1.03-1.08)$ & $2 \cdot 82(2 \cdot 23-3 \cdot 57)$ \\
\hline & $17 \cdot 2$ & $0.93(0.88-1.00)$ & $0.95(0.92-0.98)$ & $0.49(0.37-0.66)$ \\
\hline \multirow[t]{3}{*}{ Male } & $13 \cdot 6^{\dagger}$ & $1 \cdot 11(1 \cdot 03-1 \cdot 19)$ & $1 \cdot 06(1 \cdot 02-1 \cdot 10)$ & $3 \cdot 80(2 \cdot 70-5 \cdot 34)$ \\
\hline & $14 \cdot 8$ & $1 \cdot 09(1 \cdot 01-1 \cdot 18)$ & $1.03(0.99-1.08)$ & $2 \cdot 96(2 \cdot 02-4 \cdot 34)$ \\
\hline & $17 \cdot 2$ & $0.96(0.87-1 \cdot 07)$ & $0 \cdot 90(0 \cdot 85-0 \cdot 95)$ & $0.41(0.26-0.67)$ \\
\hline \multirow[t]{3}{*}{ Female } & $13 \cdot 8^{\dagger}$ & $1 \cdot 06(1 \cdot 01-1 \cdot 13)$ & $1 \cdot 07(1 \cdot 04-1 \cdot 11)$ & $3 \cdot 24(2 \cdot 48-4 \cdot 24)$ \\
\hline & $14 \cdot 8$ & $1 \cdot 04(0.98-1 \cdot 11)$ & $1 \cdot 07(1 \cdot 03-1 \cdot 10)$ & $2 \cdot 74(2 \cdot 03-3 \cdot 70)$ \\
\hline & $17 \cdot 2$ & $0.92(0 \cdot 85-1 \cdot 00)$ & $0.98(0.94-1.02)$ & $0.54(0.37-0.79)$ \\
\hline \multirow[t]{3}{*}{$0-5$ years } & $13 \cdot 7^{\dagger}$ & $1 \cdot 08(1 \cdot 03-1 \cdot 13)$ & $1 \cdot 07(1.04-1 \cdot 09)$ & $3 \cdot 37(2 \cdot 73-4 \cdot 15)$ \\
\hline & $14 \cdot 8$ & $1 \cdot 06(1 \cdot 01-1 \cdot 12)$ & $1 \cdot 05(1 \cdot 02-1 \cdot 08)$ & $2 \cdot 73(2 \cdot 15-3 \cdot 47)$ \\
\hline & $17 \cdot 2$ & $0.93(0.87-1.00)$ & $0.94(0.91-0.98)$ & $0.47(0 \cdot 35-0.64)$ \\
\hline \multirow[t]{3}{*}{$6-14$ years } & $14 \cdot 1^{\dagger}$ & $1 \cdot 06(0 \cdot 88-1 \cdot 28)$ & $1 \cdot 12(1 \cdot 02-1 \cdot 24)$ & $7 \cdot 24(3 \cdot 02-17 \cdot 35)$ \\
\hline & $14 \cdot 8$ & $1.03(0.84-1 \cdot 26)$ & $1 \cdot 13(1 \cdot 02-1 \cdot 26)$ & $6 \cdot 57(2 \cdot 46-17 \cdot 56)$ \\
\hline & $17 \cdot 2$ & $0.88(0 \cdot 67-1 \cdot 14)$ & $1.07(0.94-1.22)$ & $0 \cdot 98(0 \cdot 29-3 \cdot 29)$ \\
\hline
\end{tabular}

$* 14 \cdot 8^{\circ} \mathrm{C}$ and $17 \cdot 2^{\circ} \mathrm{C}$ represented the 75 th percentile and 95 th percentile of DTR, respectively.

$\dagger$ The peak values of humidex for total children, gender-specific and age-specific BD cases, respectively.

can affect the survival and transmission of the HFMD virus in the environment, as well as children's behavior, thereby influencing the transmission dynamics of HFMD.

The two groups in this study demonstrated different DTR impact patterns. The effect of DTR on HFMD incidence in group A generally showed a positive relationship. While the exposure-response curve in group B shown as an approximately inverted V-shape. The mean DTR in group A was 7.09 (ranged from 1 to 16 ), while the mean DTR in group B was $12 \cdot 18$ (ranged from 2 to 22). However, in this study, there were only 5443 cases in group B. More studies are needed in large DTR regions.

EV71 and CV-A16 are the predominant pathogens responsible for HFMD outbreaks worldwide [21, 22]. But few studies have examined pathogen-specific effects of meteorological factors on HFMD. Dong et al. provided a clue that mean temperature had a stronger relationship to EV71 than CV-A16 [23]. But there was no convincing evidence to conclude that significant differences exist between the influences of the mean temperature on EV71 and on CV-A16 because of the small sample size of their study. In this study, we explored the potential difference of the influence of DTR on EV71 and CV-A16. The pathogen-specific results of this study suggested that the exposure-response curve of DTR on EV71 was quite different from that of CV-A16. Large DTR had the higher risk estimates of HFMD incidence in cases of EV71 infection, while small DTR had the higher risk estimates of HFMD incidence in cases of CV-A16 infection.

The age-specific results suggested that children aged 6-14 years appeared to be more vulnerable to DTR effects. This might be partly because children aged 6-14 years play outdoors more often than younger children, which makes them have more chances of being exposed to the virus and are more easily infected by HFMD. The gender-specific results showed a greater association of DTR with HFMD for males than for females. These results may suggest gender differences in susceptibility at the host genetic level [24].

This study examined the effect of DTR on HFMD at a daily scale since the current study focused on the short-term effect of DTR on HFMD. The study based on daily data may be more suitable for the prevention and control of HFMD since it could provide more timely information and the local health department could have enough time to prepare for the potential epidemic. However, the relationship between DTR and HFMD may vary over different time scales. Further studies are needed to evaluate the effect of DTR on HFMD at different time scales such as a monthly and yearly scale.

A few limitations of this study should be acknowledged: (1) This study was ecological in nature, which did not allow us to explore individual-level association 
and limited our capacity for casual inference. (2) This study was based on surveillance data. Surveillance data for HFMD did not capture all cases. Therefore, the potential bias caused by underreporting may exist.

In conclusion, our study provided a comprehensive picture of the non-linear relationship between daily DTR and HFMD in a large province of Southwest China. Children aged 6-14 years and male children were more vulnerable to the temperature changes. Large DTR had the higher risk estimates in cases of EV71 infection, while small DTR had the higher risk estimates in cases of CV-A16 infection. Our study provides information to better understand the impact of DTR on HFMD and might have potential importance for disease prevention and control. It is important for both health practitioners and parents to be aware of the effect of DTR on childhood HFMD, and take protective strategies to reduce the associated risks. In addition, different DTR-HFMD associations among different sub-groups could be considered to optimize public health prevention strategies.

\section{ACKNOWLEDGEMENTS}

This work was supported by the National Natural Science Foundation of China (grant no. 81402766) (FY) and the National Natural Science Foundation of China (grant no. 81602935) (TZ).

\section{AUTHOR CONTRIBUTIONS}

FY and YM conceived of the project concept; QL and YL cleared the data. FY, XZ, YM and TZ performed the data analysis, model development and interpretation. FY and XL drafted the manuscript. All of the authors have read and approved the final manuscript.

\section{DECLARATION OF INTERESTS}

None.

\section{REFERENCES}

1. Gopalkrishna V, et al. Circulation of multiple enterovirus serotypes causing hand, foot and mouth disease in India. Journal of Medical Microbiology 2012; 61(3): 420-425.

2. Xing W, et al. Hand, foot, and mouth disease in China, 2008-12: an epidemiological study. The Lancet Infectious Diseases 2014; 14(4): 308-318.
3. Jiang M, et al. Autopsy findings in children with hand, foot, and mouth disease. New England Journal of Medicine 2012; 367(1): 91-92.

4. Ooi MH, et al. Clinical features, diagnosis, and management of enterovirus 71. The Lancet Neurology 2010; 9(11): 1097-1105.

5. Ang LW, et al. Epidemiology and control of hand, foot and mouth disease in Singapore. Annals Academy of Medicine Singapore 2009; 38: 106-112.

6. Chua KB, Kasri AR. Hand foot and mouth disease due to enterovirus 71 in Malaysia. Virologica Sinica 2011; 26 (4): 221-228.

7. Fujimoto T, et al. Hand, foot, and mouth disease caused by coxsackievirus A6, Japan, 2011. Emerging Infectious Diseases 2012; 18(2): 337-339.

8. Ni H, et al. Epidemiological and etiological characteristics of hand, foot, and mouth disease in ningbo, China, 2008-2011. Journal of Clinical Virology 2012; 54(4): 342-348.

9. Huang Y, et al. Effect of meteorological variables on the incidence of hand, foot, and mouth disease in children: a time-series analysis in Guangzhou, China. BMC Infectious Diseases 2013; 13(1): 134.

10. Onozuka D, Hashizume M. The influence of temperature and humidity on the incidence of hand, foot, and mouth disease in Japan. Science of the Total Environment 2011; 410: 119-125.

11. Wei $\mathbf{J}$, et al. The effect of meteorological variables on the transmission of hand, foot and mouth disease in four major cities of shanxi province, China: a time series data analysis (2009-2013). PLoS Neglected Tropical Diseases 2015; 9(3): $\mathrm{e} 0003572$.

12. Zhu L, et al. The impact of ambient temperature on childhood HFMD incidence in inland and coastal area: a Two-city study in shandong province, China. International Journal of Environmental Research and Public Health 2015; 12(8): 8691-8704.

13. Xu M, et al. Non-Linear association between exposure to ambient temperature and children's hand-foot-andmouth disease in Beijing, China. PLOS ONE 2014; 10 (5): e0126171.

14. Onozuka D. The influence of diurnal temperature range on the incidence of respiratory syncytial virus in Japan. Epidemiology and Infection 2015; 143(04): 813-820.

15. $\mathbf{X u} \mathbf{J}$, et al. Impact of temperature variability on childhood hand, foot and mouth disease in Huainan, China. Public Health 2016; 134: 86-94.

16. Xu Z, Hu W, Tong S. Temperature variability and childhood pneumonia: an ecological study. Environmental Health 2014; 13(1): 51.

17. Hii YL, Rocklöv $\mathbf{J}, \mathbf{N g} \mathbf{N}$. Short term effects of weather on hand, foot and mouth disease. PLOS ONE 2011; 6 (2): e16796.

18. Ma E, et al. Is hand, foot and mouth disease associated with meteorological parameters? Epidemiology and Infection 2010; 138(12): 1779-1788.

19. The Ministry of Health of China. Hand, Foot and Mouth Disease Prevention and Control Guideline, China. 2009 (http://wwwgoven/gzdt/2009_06/04/content_1332078htm). Accessed 4 June 2017. 
20. Gasparrini A, Armstrong B, Kenward M. Distributed lag non-linear models. Statistics in Medicine 2010; 29(21): 2224-2234.

21. Mao Q, et al. Coxsackievirus A16: epidemiology, diagnosis, and vaccine. Human Vaccines \& Immunotherapeutics 2014; 10(2): 360-367.

22. Yip CC, et al. Human enterovirus 71 epidemics: what's next? Emerging Health Threats Journal 2013; 6(1): 19780.
23. Dong W, et al. The effects of weather factors on hand, foot and mouth disease in Beijing. Scientific Reports 2016; 6: 19247 .

24. Chen T-C, et al. Combining multiplex reverse transcription-PCR and a diagnostic microarray to detect and differentiate enterovirus 71 and coxsackievirus A16. Journal of Clinical Microbiology 2006; 44(6): 2212 2219. 